\title{
Membrane Cleaning
}

\author{
José Miguel Arnal, Beatriz García-Fayos and María Sancho \\ Instituto de Seguridad Industrial, \\ Radiofísica y Medioambiente (ISIRYM) / Universitat Politècnica de València \\ Spain
}

\section{Introduction}

In last years, desalination by reverse osmosis ( $\mathrm{RO}$ ) process has experienced a significant development, and it has become one of the major technologies for producing potable water throughout the world. Despite this relevant growth, reverse osmosis, and membrane processes in general, has several drawbacks to overcome. Specifically, fouling of membranes is the most important problem in reverse osmosis desalination since economics of the process is still highly influenced by membrane fouling rate and effectiveness of fouling control.

\subsection{Fouling agents}

Membrane lifetime and permeate productivity are primarily affected by concentration polarization and fouling at the membrane surface. IUPAC defines membrane fouling as "a process resulting in loss of performance of a membrane due to the deposition of suspended or dissolved substances on its external surfaces, at its pore openings or within pores". The main mechanisms of membrane fouling are the following (Goosen et al., 2004):

- Adsorption, due to chemical affinity or interaction between solutes and membrane material. This can happen at membrane surface or inside the pores.

- Pore blockage, when solutes go inside membrane pores.

- Gel formation, as a consequence of molecule accumulation at the film layer of the membrane. This is very typical in solutions containing proteins.

- Biofouling, cause by bacterial adhesion and growth at membrane surface, besides the production of extracellular polysaccharides (EPS) by some genera of bacteria, which in fact are the substance responsible for the biofilm (Baker \& Dudley, 1998).

In desalination by $\mathrm{RO}$ membranes, the most common fouling types are: organic fouling due to natural organic material (NOM) such as humic and fulvic acids, protein and carbohydrate; inorganic fouling due to depositions of inorganic scales (mainly $\mathrm{BaSO}_{4}$, $\mathrm{CaSO}_{4}, \mathrm{CaCO}_{3}$ ); and biofouling due to microbial attachment to membrane surface followed by growth and multiplication (Chesters, 2009; Al-Amoudi \& Lovitt, 2007). Biofouling is one of the most serious forms of membrane fouling because once it forms; biofilm is very difficult to remove.

\subsection{Consequences of fouling in membrane performance}

As a result of membrane fouling, membrane resistance increases with time due to accumulation of foulants on membrane surface and/or inside the membrane (Tay \& Song, 
2005). The main consequences of fouling are: flux decline, permeate quality deterioration and energy consumption increase. Since operating costs of reverse osmosis highly depend on membrane useful life (membrane replacement involves $20-30 \%$ of the operating costs), fouling control is essential for increasing membrane operational life and thus reducing economics of the process (Butt et al., 1997).

\subsection{Preventing and minimizing fouling}

Possible ways for fouling control are feed pre-treatment, operation conditions and membrane cleaning.

\subsubsection{Pretreatment}

It is essential to establish a good pre-treatment to avoid or minimize fouling, so productivity loss would be lower (Figure 1). Nevertheless, in spite of a good pre-treatment, membranes have to be periodically cleaned to remove reversible fouling. In case pre-treatment was inadequate, higher frequency of cleanings will be necessary, and the restoration of membrane performance will be worse (Sadhwani \& Veza, 2001).

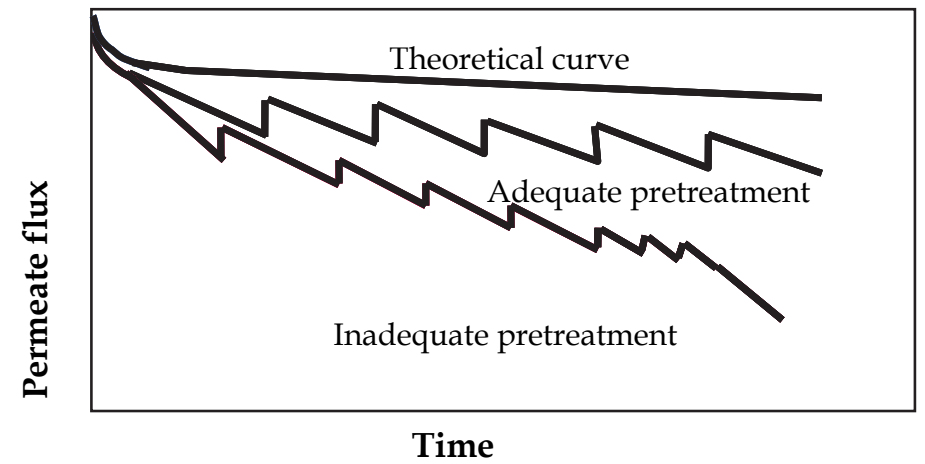

Fig. 1. Influence of pre-treatment on membrane productivity

\subsubsection{Operation conditions}

In spite of the pre-treatment of feed water, operation conditions such as temperature, pressure and crossflow velocity can be considered to reduce fouling (Mohammadi et al., 2002). Furthermore, it has been showed that there is a critical permeate flux, operating above which productivity can be maximized at the same time that membrane cleaning frequency is reduced (Goosen et al., 2004).

\subsection{Modes of fouling detection and characterization}

It is vey important to know the characteristics of the foulant deposited on the membrane in order to select the most effective cleaning procedure. The best method of foulant identification is membrane autopsy after fouling, which is considered as an off-line method for fouling characterization. However, this is a destructive and expensive method that may be considered to enhance system performance when fouling is complex, when cleaning fails to restore membrane performance (Pontié et al., 2005; Al-Amoudi \& Lovitt, 2007), and when membranes result damaged after cleaning. 
Membrane autopsies are characterized for using techniques that are able to identify the inorganic and organic material found at the membrane surface:

- Scanning Electron Microscope (SEM) and Scanning Electron Microscope coupled with Energy Dispersed X-ray (SEM-EDX) to determinate inorganic foulant elemental composition.

- Fourier Transform Infrared Spectroscopy (FTIR) to identify organic compounds.

- Targeted Energy Dispersive X-Ray Analysis (T-EDXA) as an indication of inorganic compounds.

For identifying biofouling, several techniques can be achieved during autopsies, such as:

- Total Direct Count, which determinates in the membrane surface the number of bacteria dead or alive, growth in a medium and counted with microscope per $\mathrm{cm}^{2}$.

- Heterotrophic Plate Count, which scrapes a sample of the biomass attached on the membrane surface to determinate colony forming units (CFU) growth in a special medium.

- Adenosine Triphosphate (ATP), which is considered an essential indicator of living bacteria and gives a measure of the amount of active biomass over the membrane surface.

Even though, recent trends about fouling detection and characterization are pointed to develop and use non-destructive and visual on-line methods that help to study the fundamentals of membrane fouling, and also work as indicators and early warnings fouling detectors in real-time. Some examples of this recently developed technology are the following:

- Membrane Fouling Simulator (MFS): uses the same materials as spiral-wound RO and NF membranes. This tool is very useful to study and monitor fouling and biofouling over spiral wound membranes, monitoring pressure drop, in situ-real time observation of membrane surface and multiple analysis of coupons sampled form the membrane. The small size and low water and chemical use of the MFS facilitate to perform systematic parallel studies. With the MFS, fouling of membranes applied in water treatment can be characterized (Vrouwenvelder et al., 2006; Vrouwenvelder et al., 2007a; Vrouwenvelder et al., 2007b).

- Visual Observation methods: recently, a new high-pressure optical membrane module has been developed to enable direct visual observation of bacterial deposition onto reverse osmosis membranes under practical seawater desalination operating conditions. The new optical membrane module withstands pressures up to $8.3 \mathrm{MPa}$ while allowing high transmission of UV and visible light. Computational fluid dynamic analyses of the optical module suggest practically relevant cross-flow hydrodynamic conditions exist through the viewing area of the optical window (Huang et al., 2010).

- In-line biofouling monitor: this recent development is based on accurate monitoring of normalized pressure drop, flow and temperature across first stage. It is very useful to monitorize biofouling and scaling.

- Ultrasonic Time-Domain Reflectometry (UTDR): as an in situ, non-invasive real-time technique has been successfully used to quantify membrane fouling and cleaning. This ultrasonic technique is useful for quantitative study of the effect of magnetic fields on $\mathrm{CaCO}_{3}$ scale deposition on the membrane surface during cross-flow nanofiltration (NF) and also in ultrafiltration (UF) membranes (Li et al., 2002). These results have been corroborated by comparing this technique with SEM and flux decline data also (Li et al., 2007). 
- Magnetic Resonance Imaging (MRI): this has been recently applied to biofouling studies of RO membranes, identifying both biofilm accumulation within the module and the resultant effects on water flow. MRI thus offers an in situ and non-destructive method to quantify biofilm directly. It is also a tool for direct studies of chemical cleaning of biofouled RO membranes, specially for studying cleaning effectiveness (Creber et al., 2010).

There are also alternative methods that help to identify fouling and the convenience of cleaning, such as chemical and biological analysis of the current feedwater, and the analysis of acid, caustic and distilled water extracts of the prefilter (Graham et al., 1989).

In fact, there are some parameters that can help to determinate the fouling potential capacity of feed water. The most usual ones are the following:

- Silt Density Index (SDI): is a common parameter applied for the fouling potential of feed water for Reverse Osmosis and Nanofiltration membranes. It is based on the measurement of plugging a membrane filter having $0.45 \mu \mathrm{m}$ at a pressure of $210 \mathrm{kPa}$. Even though it has been reported several deficiencies about the use of this parameter, it is still used in operation plants as fouling indicator.

- Modified Fouling Index (MFI): developed to overcome the main deficiencies of SDI, it is performed in the same equipment that SDI and it is based on the occurrence of cake filtration during a filtration test in RO and NF membranes.

- MFI-UF: recently developed, this parameter has been used to detect fouling potential capacity due to particles smaller than $0.45 \mu \mathrm{m}$, in RO and NF membranes. It requires more sophisticated equipment and it is not yet standardized.

- Langelier Saturation Index (LSI): this parameter correlates the presence of calcium carbonate with its potential precipitation. It is commonly used for low salinity waters.

- Stiff \& Davies Index (S \& DI): this is similar to LSI, but more accurate for high salinity waters, since it adds the effect of ionic strength and temperature.

In general, fouling removal must be done when some of the following situations are reached:

- $\quad 10-15 \%$ of permeate flux decline

- $\quad 10-15 \%$ of permeate solute concentration increasing

- $\quad 15-20 \%$ of pressure drop increase in a pressure vessel

When some of these situations occurred, membrane must be cleaned to restore system performance. The cleaning procedure depends mainly on the type of fouling.

\section{Conventional methods of cleaning}

Membrane cleaning methods can be divided into physical, chemical and physio-chemical. In practice, physical cleaning methods followed by chemical cleaning methods are widely used in membrane applications. However, only the chemical cleaning methods are widely applied for RO desalination.

\subsection{Physical cleaning methods}

Physical cleaning methods use mechanical forces to dislodge and remove foulants from the membrane surface. Physical methods include sponge ball cleaning, forward and reverse flushing, backwashing, air flushing (also called air sparging, air scouring or air bubbling) and $\mathrm{CO}_{2}$ back permeation (Ebrahim, 1994; Al-Amoudi \& Lovitt, 2007). Ultrasonic, electrical fields and magnetic fields are other physical cleaning methods that are described in detail in non-conventional cleaning methods point of this work. 


\subsubsection{Sponge ball cleaning}

In this method, sponge balls made of polyurethane or other materials are inserted into the membrane modules for a few seconds for scrubbing the foulant from membrane surface (Ebrahim, 1994). Sponge balls are normally used for cleaning large diameter tubular membranes when treating heavily polluted solution such as wastewater and industrial process water (Psoch \& Schiewer, 2006).

\subsubsection{Forward and reverse flushing}

Forward flushing consists in pumping permeate water at high cross-flow velocity through the feed side in order to remove foulants from the membrane surface (Ebrahim, 1994). Because of the more rapid flow and the resulting turbulence, particles absorbed to the membrane are released and discharged. In the reverse flushing method the direction of the permeate flush is alternated for a few seconds in the forward (feed to brine) and for a few seconds in the reverse direction (brine to feed) (Figure 2). Forward flush techniques are particularly useful in removing colloidal matter.

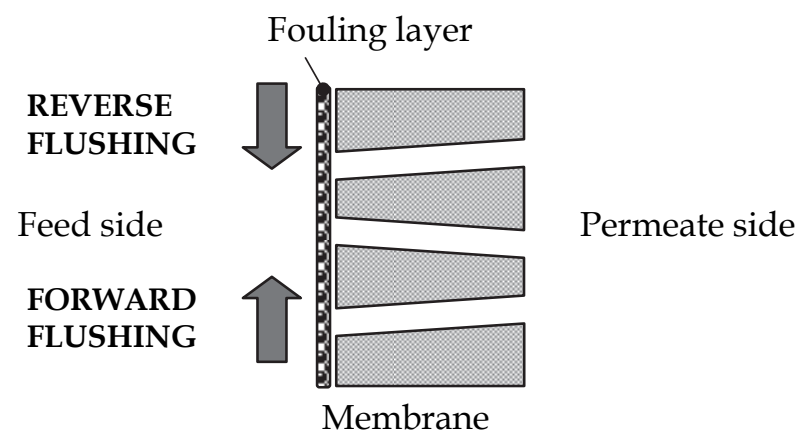

Fig. 2. Cleaning flow direction in forward and reverse flushing

\subsubsection{Backwashing}

This is a reversed filtration process in which permeate is flushed through the membrane to the concentrate side. In porous membranes, when backward flush is applied, the pores are flushed inside out. The pressure on the permeate side of the membrane is higher than the pressure within the membranes, causing the pores to be cleaned (Figure 3).

In reverse osmosis membranes, backwash is based on flow induced by osmotic pressure as direct osmotic cleaning. This cleaning process is based on negative driving pressure between the operating pressure and the osmotic pressure of the water solution in the feed side. This can be done either by reducing operation pressure below the osmotic pressure of the feed solution or by increasing the permeate pressure (Sagiv \& Semiat, 2005). Backflow from the permeate to the feed side of the membrane expands the thickness of the fouling layer and fluidizes it. After this, a forward flush is usually used to wash out the detached layer or dilute the fouling layer. The best cleaning performance is generally reached optimizing the two flows (forward flow and backflow). Some significant factors affecting physical cleaning when combining forward and backward flushing are production interval between cleans, duration of backwash and pressure during forward flush (Chen et al., 2003). 


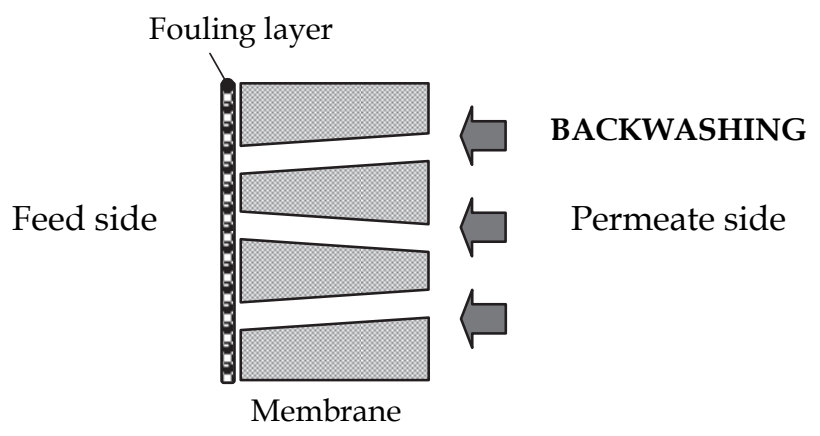

Fig. 3. Cleaning flow direction in backwashing

A main factor of the backwash cleaning is the driving force, which results from a combination of concentrations and applied pressures from both sides of RO membrane. From the point of view of operating conditions, backwash cleaning may be divided into two cases: (1) with zero feed velocity and applied pressure, and (2) with feed velocity and pressure. Some works have shown that methods without pressure seem to have some advantages on methods with pressure (Sagiv \& Semiat, 2010).

From the point of view of salt concentration difference between both sides of membranes, there is recent research on the use of hypersaline solutions in the feed side, which is described in more detail in section 3.1 of this work.

\subsubsection{Air flushing}

The air flushing or air sparging method generates a two phase flow to remove external fouling and thus reduces the cake layer deposited on the membrane surface. There are several flow patterns possible depending on the superficial liquid and air velocities. It has been showed that slug flow is the most effective pattern to enhance mass flow (Psoch \& Schiewer, 2006; Mercier et al., 1997). The type of gas used for the sparging also seems to have an influence on the cleaning efficiency. In a recent research, it has been shown that water $/ \mathrm{CO}_{2}$ mixture performes better cleaning results in comparison to water/ $\mathrm{N}_{2}$ mixture (Ngene et al., 2010). Air sparging can be applied either during the course of filtration to reduce fouling deposition (Cui \& Taha, 2003; Mercier et al., 1997; Cabassud et al., 2001) or periodically to remove already formed deposits. Air sparging is typically applied in MF and UF membranes, and it seems to work best for tubular and flat sheet membranes and to a lesser extent in hollow fiber and spiral wound modules (Cui \& Taha, 2003). Anyway, it is clear that the use of air leads to an enhancement of flux in MF and UF. This positive effect is due to the presence of air bubbles which increase turbulence in the feed side of the membrane, thus increasing permeate flux as well as solute separation efficiency (Cabassud et al., 2001; Ducom \& Cabassud, 2003).

There have been little attempts to apply air sparging in NF membranes. In some studies, air sparging was applied to prevent fouling during NF, and it was prooved that poor benefits can be expected from air sparging in case of solutions containing only salt in water (Ducom \& Cabassud, 2003). (Cornelissen et al., 2007) used air/water cleaning for biofouling control showing that the best results in spiral wound NF modules were obtained when combining daily copper sulphate dosing with sporadic air/water cleaning. 
More recently, (Qaisrani \& Samhaber, 2011) have evaluated the potential of air sparging and backflushing for MF membrane regeneration. They have found that the combination of backflushing and air bubbling is the best method for improving membrane performance both in terms of fouling control and membrane cleaning time.

\subsection{5 $\mathrm{CO}_{2}$ back permeation}

This is a method traditionally used for hollow fiber configuration in which $\mathrm{CO}_{2}$ gas is forced from the permeate side through the internal fiber and out through them (Ebrahim, 1994). More recently, (Fritsch \& Morau, 2008) applied a $\mathrm{CO}_{2}$ backpulsing system for cleaning a tubular MF membrane used in a dairy industry. They state that this is a very promising technique for maintaining a greater and more stable permeate fluxes.

\subsection{Chemical cleaning methods}

Membrane fouling can be classified as physically reversible fouling which can be totally eliminated by physical cleaning or certain pretreatment, and physically irreversible fouling which cannot completely removed by physical cleaning or pretreatment (Hiroshi et al., 2007, as cited in Gao et al., 2011). Such irreversible fouling can only be overcome by chemical cleaning, which has to be limited to a minimum frequency since repeated chemical cleaning may affect membrane life (Kimura et al., 2004).

Chemical cleaning is the most common membrane cleaning method, especially in reverse osmosis membranes. In this type of cleaning, the choice of the cleaning agent is critical. The optimal selection of the cleaning agent depends mainly on membrane material and type of foulant. These agents must be able to dissolved most of the deposited materials on the surface and removed them from the surface but not damaging membrane surface, thus maintaining membrane properties. Commercial cleaning products are often, Most chemical cleaning agents are commercially available, they are often mixtures of compounds, and many of them are recommended by membrane manufacturers according to the type of foulant, although in most cases the actual composition is not clearly specified (Ang et al., 2006). Anyway, in general acid (nitric, phosphoric, hydrochloric, sulphuric and citric) are often used to remove precipitated salts or scalants, while alkaline cleaning is suitable for organic fouling removal. Other categories of chemical cleaning agents are: metal chelating agents, surfactants and enzymes (Mohammadi et al., 2002). In addition, disinfectants $\left(\mathrm{O}_{3}\right)$, oxidants $\left(\mathrm{H}_{2} \mathrm{O}_{2}, \mathrm{KMnO}_{4}\right)$ or sequestration agents (EDTA) are often used for chemical cleaning of membranes (Lin et al., 2010).

Table 1 summarizes the most suitable and usual cleaning agents according to the type of fouling (Fritzmann et al., 2007).

\begin{tabular}{|c|c|}
\hline Type of fouling & Chemical agent \\
\hline Colloidal & $\mathrm{NaOH}$ solutions, chelating agents and surfactants \\
\hline Organic & $\mathrm{NaOH}$ solutions, chelating agents and surfactants \\
\hline Metal oxides & Citri acid with low pH or $\mathrm{Na}_{2} \mathrm{~S}_{2} \mathrm{O}_{4}$ \\
\hline Silica & $\mathrm{NaOH}$ solutions with high $\mathrm{pH}$ \\
\hline Carbonate scales $\left(\mathrm{CaCO}_{3}\right)$ & Citric acid or $\mathrm{HCl}$ with low pH \\
\hline Sulphate scales $\left(\mathrm{CaSO}_{4}, \mathrm{BaSO}_{4}\right)$ & $\mathrm{HCl}$ solutions or sequestration agents (EDTA) \\
\hline Biofilms & $\begin{array}{c}\mathrm{NaOH} \text { solutions, chelating or sequestration agents, } \\
\text { surfactants and disinfectants }\end{array}$ \\
\hline
\end{tabular}

Table 1. Cleaning solutions according the type of foulant 
A cleaning cycle generally includes several stages: product removal, rinsing with water, cleaning in one or more steps, and rinsing with water. In order to obtain a good cleaning effect, cross-flow velocity should be higher and the pressure lower than those used during normal operation (Tragardh, 1989). A typical cleaning procedure consists of the following steps (Fritzmann et al., 2007):

- Low flow pumping of the pre-heated cleaning solution at minimum pressure.

- $\quad$ Recycling of cleaning solution until a stable temperature is achieved. In this stage, $\mathrm{pH}$ can be adjusted when necessary.

- $\quad$ Soaking the RO membranes with the cleaning solution for 1 to 15 hours, depending on the type and grade of fouling.

- High flow operation to flushed foulants and chemical solution out of the system.

When the cleaning agents come into contact with the fouled layer, some physical transformations and chemical reactions take place. Physical transformations include melting, mechanical and thermal stress, wetting, soaking and swelling, within others. The chemical reactions involved are hydrolisis, peptization, solubilization, dispersion, chelation, sequestering and suspending (Tragärdh, 1989).

Other important aspects concerning chemical cleaning are temperature, chemical concentration, $\mathrm{pH}$, pressure and flow, and time (Liikanen et al., 2002; Chen et al., 2003). Some studies suggest that there is an optimal temperature for chemical cleaning (Barlett et al., 1995). Usually, increasing temperature (always below membrane maximum temperature) increases cleaning efficiency, cross-flow velocity seems to have no effect on cleaning results, whereas increasing trans-membrane pressure may even decrease cleaning efficiency. Zero transmembrane pressure is recommended for maximum efficiency in deposit removal (Barlett et al., 1995). With regard to the time required for cleaning it varies according to the foulant and the cleaning process.

\subsection{Physico-chemical cleaning methods}

The physico-chemical cleaning methods use physical cleaning methods with the addition of chemical agents to enhance cleaning effectiveness. Physico-chemical cleaning methods are not implemented widely in the RO industry. The applications usually consist in forward flushing with permeate between cleanings when more than one chemical cleaning is used (Ebrahim, 1994), but not in a simultaneous use of physical and chemical cleaning actions.

Very few works have researched on simultaneous combination of physical and chemical methods for membrane cleaning in spiral wound membranes. (Arnal et al., 2009b) studied the cleaning of UF membranes by the application of air in combination with different chemical solutions, with the objective of testing both hydraulic and chemical actions simultaneously in spiral wound membranes. The chemical solutions used in these experiments were sodium hypochlorite, hydrogen peroxide, sodium hydroxide and deionised water. The experimental results were compared to those obtained with chemical solutions without air bubbles (Arnal et al., 2009a), and showed a significant improvement in the cleaning effectiveness when using air bubbles with chemical solutions, also when comparing the results with the ones obtained with air sparging without chemical agents.

\section{Non conventional cleaning methods}

Many techniques have been developed to overcome fouling. Backwashing and backflushing are typically used to clean membranes, while more persistent foulants are removed by the 
use of chemical reagents, as itwas described previously in section 2. However, these chemicals sometimes damage the membrane materials reducing the lifetime and efficiency of the membrane and even cause a secondary pollution over cleaned membrane. Moreover, these methods have proven to be inefficient for some kind of fouling and also create environmental issues related to the waste chemical disposal. In other cases they add costs of cleanup, handling, and transporting dangerous chemicals, waste energy by decreasing and then increasing pressures needed for the membrane system to work, and waste cleaned water (Lu et al., 2009). It has been reported that, in general, $5-20 \%$ of the operating costs of a large plant are associated to cleaning procedures (Madaeni et al., 2001). Therefore, an intense research work is being done to develop new cleaning methods, called nonconventional or emerging techniques, more efficient and more environmental safe. Some of them are being applied in $\mathrm{RO}$ membranes and others just started for MF and UF membranes.

These novel cleaning techniques are described now and specifically for RO membranes used in desalination.

\subsection{Osmotic backwashing with hypersaline solution}

Pressure driven backwashing is common practice in filtration processes, including microfiltration and ultrafiltration, offering an effective means of fouling control. However, it was not extensively employed for membranes used in desalting, due to high back-pressure required for a hydraulically driven backwash since it may rupture the composite membrane used (Ramon et al., 2010).

Osmotic backwash may be induced when the feed-side osmotic pressure exceeds the applied hydraulic pressure across the membrane. It is based on water back flow from the permeate side to the feed side driven by osmotic forces or salt (mainly $\mathrm{NaCl}$ ) concentration differences between both sides of the RO membranes. When water enters the feed channel, it dilutes the concentration polarization $(\mathrm{CP})$ layer and helps in cleaning the membrane surface to resume its original flow rate.

Based on this technology, osmotic backwash induced by the use of hypersaline solution has been developed in the last years. It is considered an innovative, effective and potentially chemical-free cleaning technique. It is performed by injecting into the feed channel a pulse of high concentration solution called hypersaline solution (HS) that can supply more than 100 bar of the cleaning force and which is used to remove the foulants from the membrane surface, specially colloidal matter and biofilm material. Hypersaline solution injection promotes direct osmosis (DO) across the RO membrane and the flow of the water from the permeate side to the feed. The reversible flow helps to dislodge any foulants and scaling on the membrane surface and promotes lifting, sweeping and removing of the $\mathrm{CP}$ layer.

In fact, hypersaline solution injection promotes different effects such as (Liberman \& Liberman, 2005):

- Lifting of an existing fouling layer due to backflow of permeate through the membrane. Even the osmotic pressure of the high-salinity solution decreases on its way, but it remains strong enough to create back permeate flow and lift foulants until it reaches the end of the pressure vessel.

- Sweeping and stripping of the lifted fouling layer. Increasing velocities inside the feed channel mechanically removes foulants from the feed and reduces the pressure drop along the pressure vessel. 
- Separation of biomass from the membrane surface due to bio-osmotic shock. Water is sucked out from cytoplasm such as bacteria, fungi and algae, cell membranes shrink and detach from the membrane surface.

- Dissolving of micro-crystals due to the ionic strength of the hypersaline solution.

Membrane cleaning by hypersaline solutions ensured stable operation with significantly improved membrane performance, consistently reduced low pressure drop and increased membrane salt rejection. The main advantages of this cleaning method are the following:

- On-line technique without interruption of the operation.

- High effectiveness.

- Low cost.

- Ease of implementation at existing facilities and in the design of new plants without great changes to plant equipment.

- Simplified disposal due to a reduction of cleaning chemicals.

- Low membrane replacement rate.

It is considered a novel backwash approach for on-line membrane cleaning in RO operation without stopping the RO pump. There are short studies about this promising technique but all of them provide a preliminary indication regarding the potential for employing an osmotic backwash useful for membrane cleaning. First studies were published by Liberman in 2005 (Liberman \& Liberman, 2005). In that work, a short injection of feed water with increased salt concentrations ( $25 \% \mathrm{NaCl}$ solution) with an associated osmotic pressure of 200 bar overcomes feed pump gauge pressure and reverse osmosis shifts to direct osmosis, leading to a permeate backwash stream through the reverse osmosis membrane, as it is shown in following figure (Figure 4).
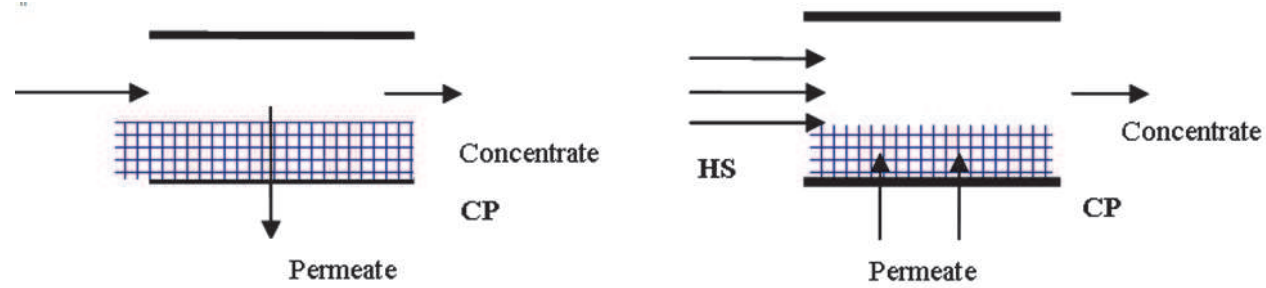

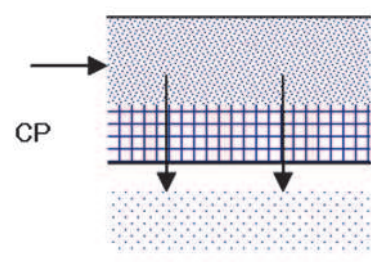

$\mathrm{RO}$

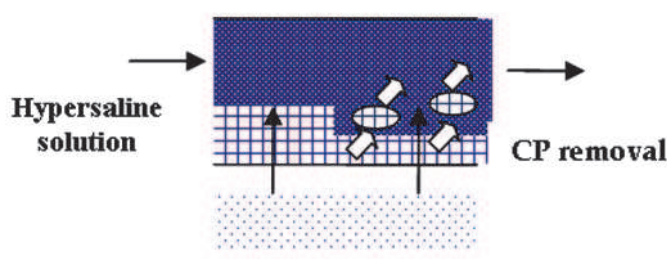

$\mathrm{DO}$

Fig. 4. Hypersaline solution backwash cleaning

In other studies, resistance of the RO membrane to water passage was considered a factor affecting the uniformity of the cleaning process. It was suggested to increase the gauge pressure at the permeate side of the membrane to a level slightly below the feed pressure of 
the raw saline solution, which is done by back pumping permeate for a few seconds. Results from that study, stated that permeate back pressure was to be at least 4 bar in order to make sure the DO backwash cleaning would be efficient. This remark increases the performance of the cleaning process but increases its cost due to investment needed to equipment for the permeate side working at high pressure (Liberman, 2004).

It was also reported the use of a super-saline solution made of $17 \% \mathrm{NaCl}$ with osmotic pressure of 170 bar could be injected into the feed stream over a few seconds in order to create a very strong net driving force of 55 bar for the DO backwash process (Liberman, 2005). Recent studies (Qin et al., 2010) employed this technique to remove fouling from a RO system fouled with a secondary-treated waste-water. Research observed a rise of the turbidity of the brine stream (from 0.6-5 NTU), indicating the foulant removal from the membrane.

Main parameters that should be studied for proper implementation of this novel technique are saline concentration, duration of the pulse injection and flow rate of hypersaline solution in compliance with feed water chemistry, configuration of the existing RO train and pumps' curves. Improper implementation of the technique can damage the membrane element (Qin et al., 2009).

For a proper choice of some major parameters, it is generally recommended that the concentration of $\mathrm{HS}$ solution injection is $5-10 \% \mathrm{NaCl}$ and the flow rate of $\mathrm{HS}$ solution is close to the normal RO operation as a starting point.

To date, most recent studies about the use of hypersaline solutions for osmotic backwashing show the importance of the duration of pulse duration. Pulse duration should be longer than the residence time for a maximum achievable cycle-averaged permeation rate. A shorter pulse is ineffective in inducing osmotic permeation particularly towards the end of the channel. In fact, short pulse is significantly diluted on the membrane surface to the point where its concentration may drop below that required for inducing osmotic flow. The pulse concentration and duration must be optimized if efficient osmotic cleaning is to be achieved throughout the full length of a membrane train (Ramon et al., 2010).

\subsection{Ultrasonic fields}

Application of ultrasound for enhancing permeation in membrane processes has been extensively studied, specially for enhancing microfiltration (Kyllönen et al., 2005) and ultrafiltration (Chen et al., 2006; Juang \& Lin, 2004; Saxena et al., 2009) membrane separation, and it has also been considered as a pretreatment to minimize fouling specially due to particulate or organic matter.

Ultrasound is defined at frequencies ranging from $16 \mathrm{kHz}$ to $1019 \mathrm{kHz}$ produced by electromechanical transducers based on piezoelectric effect. The basic physical phenomenon behind the effect of ultrasound is cavitation, that starts between this range of frequency, and it is promoted by the pass of the ultrasound waves through the liquid medium in a series of alternate compression and expansion cycles. Cavitation mainly promotes formation, growth and implosive collapse of bubbles in the liquid that has significant mechanical and chemical effects. In fact, it is reported that each cavitation bubble generates temperatures of 4000-6000 $\mathrm{K}$ and pressures of 100-200 MPa, acting as active "hot spots" (Feng et al., 2006). The acoustic streaming and shear forces imposed by cavitation bubbles reduce the fouling on membrane surface. Further, when a cavitating bubble is oscillating near a solid surface, it does so asymmetrically, resulting in the generation of microjets (microstreams) of high velocity and shock waves ( $\mathrm{Li}$ et al., 2002) as it is shown in next figure (Figure 5). Fluid flowing at these 
high velocities can decrease the thickness of boundary layer and diffusional resistance and therefore enhance the rates of mass transfer.

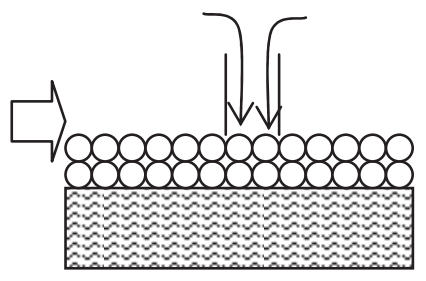

Microjets effects near CP

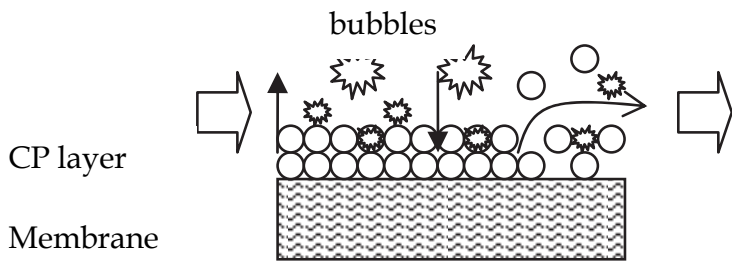

Growth and implosion bubbles near CP

Fig. 5. Ultrasound effect on membrane cleaning

Main advantages of ultrasound cleaning are the following (Lu et al., 2009):

- Membranes can be cleaned while they are in use.

- There are no secondary pollutants and problems of transporting and handling of dangerous chemicals as in the chemical cleaning.

- Hydrogen peroxide $\left(\mathrm{H}_{2} \mathrm{O}_{2}\right)$ and hydroxyl free radical $(. \mathrm{OH})$ produced by ultrasound can be used for disinfection of the distribution systems of drinking water, reducing the use of chlorine that produces carcinogenic by-products and thus is harmful to humans.

Variables needed to be investigated include the intensity of the ultrasound field, the solute concentration and the irradiation time to increase effectivity of the process without damaging microstructure of the membrane surface due to sonication process.

Nowadays, there are short studies that reported the performance of applying this technology to reduce membrane fouling in reverse osmosis membranes specifically. The patent of Harvey (Harvey, 1965, as cited in Feng et al., 2006) proposed the use of an acoustic liquid whistle or ultrasound transducers to produce cavitation to prevent clogging of membranes and to remove concentration-polarisation in a water desalination process with semi-permeable reverse osmosis membranes.

Just Feng (Feng et al., 2006) reported that on-line ultrasonic defouling of the polyamidebased reverse osmosis membranes resulted in a significant increase in the permeate flux. In fact inorganic foulants such as $\mathrm{CaSO}_{4}$ and $\mathrm{Fe}(\mathrm{OH})_{3}$ and organic foulants such as carboxymethyl cellulose were effectively removed from the membrane surface.

In spite of this, it has been demonstrated in various laboratory scale studies that ultrasound can be used very effectively to clean membranes; so far, there are no ultrasound technologies that are used in a large-scale drinking water treatment. Main reasons for this situation are:

- The cost of energy needed by ultrasound cleaner would be high.

- Ultrasound transducers that could handle a high power to produce cavitations would be very costly, bulky, and brittle.

More research needs to be done in the ultrasound field application to improve ultrasound transducers and to reduce energy cost of the cleaning process.

\subsection{Electric fields}

Electric field is considered as another way to reduce membrane fouling but also a way to favour separation process. Electric field is based on a phenomenon generally referred as 
electrokinetics. Electrokinetics is defined as the "liquid flow that occurs along a solid/liquid interface as a result of an applied potential gradient or conversely to the potential developed when a liquid is made to flow along an interface" (Sennett \& Oliver, 1965). This phenomenon has a beneficial effect in the filtration process which contributes as an additional driving force without increasing shear stress.

As a result of the electrokinetics, electrophoresis and electroosmosis effects are observed:

- Electrophoresis is related to the movement of the solids or charged species (such as proteins).

- Electrosmosis phenomenon is about the movement of the fluid, such as permeation of the fluid through a porous medium (membrane).

Application of an electric field on the membrane surface would potentially attract the particles from the membrane surface, lifting them and carrying them over. The electric field imposes an electrophoretic effect on the charged molecules dragging them away from the membrane surface, reducing the concentration polarization layer and increasing the flux. Besides the occurrence of electrophoresis and electroosmosis, other effects such as electrolysis, Joule's heating or ion migration also happen due to the application of an electric field, which can affect filtration performance and fouling process.

The applied electric field strength depends on the conductivity of the feed, electrode placement and material. The electrochemical properties of the membrane surface and the dispersed materials or solutes can also have a significant influence on the nature and magnitude of the interactions between the membrane and the substances being used, and their separation characteristics. Finally, zeta potential and charge of the species present in the feed should be studied with the aim of optimizing the application of this technology as it is represented in next figure (Figure 6).

Different kinds of cell and configurations are used, being most of them flat sheet or spiral wound membranes with platinum electrodes. Process used to be enhanced by the presence of dynamic turbulence promoters as static metal deployed sheet, oxygen bubbles or activated alumina in UF membranes (Mameri et al., 1999). In other cases, gases generated during the resulting water electrolysis have a "sweeping action" on the membrane surface, that keeps the membrane surface clean.

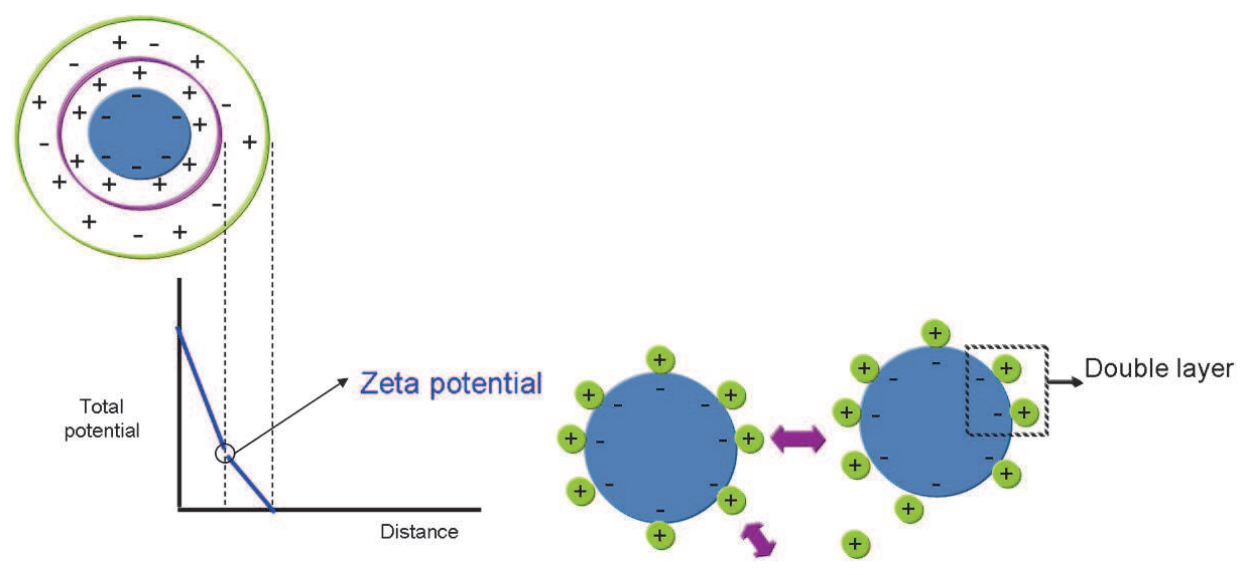

Fig. 6. Zeta potential of a colloidal particle 
Main advantage of this cleaning technique is that electric field can be applied in the work cycle without interruption, in a similar way of hypersaline and ultrasound cleaning techniques described before. Electric field is applied either continuously (Iritani et al., 2000) or intermittently, being this second option more suitable because it reduces energy consumption, reduces the heat production and also reduces the induction time to obtain undesirable chemical changes in the process due to electrochemical reactions (Oussedik et al., 2000; Weigert et al., 1999, Webster et al., 2000). Best results have been obtained with electric fields of high voltage, intermittently applied and long time applied (Ahmad et al., 2002).

Therefore, it is considered an emerging technology for its application in $\mathrm{RO}$ due to some disadvantages that needed more research such as:

- $\quad$ The use of uneconomic power levels to decouple the solutes from the permeate or bulk stream which can limit this approach in water treatment using RO.

- The cost of the electrodes. The electrode materials chosen should be compatible with the membrane material as well as with the feed stock being processed. Furthermore, the electrode areas should not interfere with the feed and permeate flows (Jagannadh et al., 1996).

Main research about the use of this technique for membrane cleaning is related with UF membrane. Among all the research reviewed, Tarazaga has important results, obtained with their studies with bovine plasma over UF membranes. These studies demonstrate the huge potential of applying an electric field under cross-flow filtration, to reduce membrane fouling of the membrane (Tarazaga et al., 2006a). Application of a rectified medium wave pulse made an increase of the permeate flux till values almost initial, being proportional the increase of the flux to the increase in the electric field. Polarization concentration and fouling of the membranes became a reversible phenomenon due to application of electric fields in different cycles, allowing to recover permeate initial flux in all the experiments. Even more, some studies state that the use of electric fields has demonstrated that the initial permeate flux of protein UF fouled membranes can be restored almost instantaneously by means of an exponential curve (Tarazaga et al., 2006b).

Application of an electric field used to be very effective for protein separation, because they present an electric charge that helps protein separation by ultrafiltration (Saxena et al., 2009). This technique is called electro-ultrafiltration and is represented in next figure (Figure 7). It is also applied in membranes previously fouled with colloidal matter or oils.

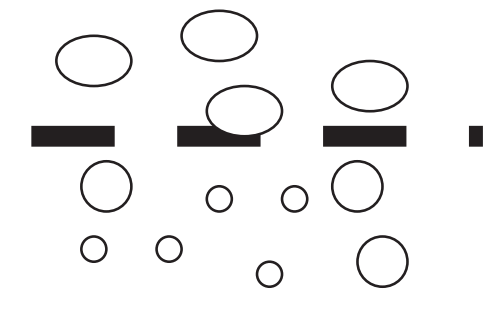

Membrane process

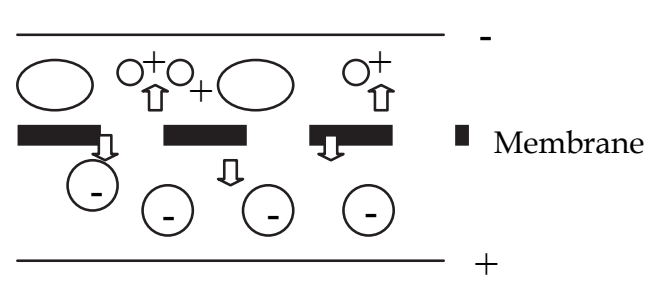

Membrane process with electric field

Fig. 7. Effect of the electric field in separation process 
Some specific studies related with RO membranes are published. Romo and Pitts (Romo \& Pitts, 1998), stated the application of electric field was effective in dispersing colloidal particles contained in water from a soft drink bottling plant. The effect of the high voltage electric field ( $30 \mathrm{kV}$ DC power supply) created by a ceramic electrode on RO membranes kept them free from biological deposits during 9 months operation. After 11 months chemical cleaning was performed as a preventive maintenance measure. Performance of the membranes was not enhanced by chemical cleaning, proving that membranes had remained clean throughout the testing period with the electric field.

\subsection{Magnetic fields}

Calcium carbonate precipitation has been the focus of numerous investigations because of its importance in several industrial processes. For instance, it is involved in many industrial applications as pigment, brightener filler, adsorbent, and in different biomedical uses. However, calcium carbonate scale deposition induces important damage in the domestic, agricultural or industrial installations using natural waters (pipe blocking, membrane clogging, efficiency decay of heaters or heat exchangers, etc.) (Alimi et al., 2009). Various methods were used to prevent scaling, for example by water decarbonation using electrochemical processes, seeding or acid addition. Other way consists in blocking the nucleation and crystal growth by adding chemical inhibitors called antiscalants. However, when these strategies do not give enough good results, alternative non-chemical processes have therefore been performed. They are preferable due to the fact that they do not change the properties of water. In particular, magnetic water treatments may be considered, due to some advantages such as low cost, simple operation and no harm to the environment.

It is believed that magnetic water treatment decreases the hardness of water and either reduce and remove existing scale or produce a softer and less tenacious scale. This effect is because magnetic treatment alters the morphology and adhesion of calcium carbonate scale, changing calcite, into aragonite. These are the two common natural forms of $\mathrm{CaCO}_{3}$, with rhombohedra and orthorhombic crystal structures, respectively. Aragonite has higher density, is more soluble and does not precipitate, avoiding and reducing scale formation. Even though, there is some dispute as to whether the deposits of calcium carbonate from magnetically treated water are predominantly: calcite or aragonite (Coey \& Cass, 2000).

Scaling or precipitation fouling of reverse osmosis and nanofiltration membranes is also a common phenomenon occurring wherever the solubility of any sparingly soluble salt in the feed water is exceeded. Inorganic scale formation on the membrane shortens the life of the membrane system and increases operating and maintenance costs. Sometimes may also lead to physical damage of membranes due to the difficulty of scale removal and to irreversible membrane pore plugging. The most common constituents of scale are $\mathrm{CaCO}_{3}, \mathrm{CaSO}_{4} .2 \mathrm{H}_{2} \mathrm{O}$ and silica, while other potential scaling species are $\mathrm{BaSO}_{4}, \mathrm{SrSO}_{4}, \mathrm{Ca}_{3}\left(\mathrm{PO}_{4}\right)_{2}$ and ferric and aluminium hydroxides. A certain degree of fouling control can usually be achieved by optimisation operating conditions with specific reference to factors having an influence on concentration polarisation $(\mathrm{CP})$. In other cases, chemical reagents are needed to reduce scaling by lowering $\mathrm{pH}$, adding antiscalants or a mix of both. However, when these strategies do not give enough good results, alternative non-chemical processes have therefore been performance, by inducing turbulence in the module to reduce boundary layer (Baker et al., 1997). 
Magnetic fields are applied normally in the feed flow, in the storage tank or even over pipe that takes the flow into the membrane module. Devices for generating magnetic fields is not normalized, and some of the researchers use electromagnets and others permanent magnets. They should accomplish a dynamic magnetic treatment, since the solution has to move fast enough through the magnetic field. Better results are obtained for systems with continuous recirculation where water is exposed to magnetic fields several times (Baker et al., 1996).

Al-Qahtani (Al-Qahtani, 1996) concluded that pretreatment of the solution before entering to the RO membrane module, decreases salt concentration of the permeate when comparing results to those obtained in the same process but with untreated feed flows. Application of a magnetic field improved conductivity and $\mathrm{pH}$ of the treated solution and concentrate of $\mathrm{RO}$ membrane increased when magnetic treatment was introduced. Other researchers such as Vedavyasan (Vedavyasan, 2001) stated that fouling improves when magnetic field is applied, decreasing energy cost in a rate of $18 \%$ and cleaning cost in a $33 \%$ percentage.

However, Baker (Baker et al., 1996), stated that magnetic field treatment for cleaning membranes was not useful to prevent scaling when RO membranes are working at a high recovery rate in systems with saturated solutions of calcium carbonate in one step systems and with recirculation. Opposite results were observed in NF membranes by $\mathrm{Li}$ (Li et al., 2007).

Since some results are contradictory, more research is needed about the mechanism that magnetic field has over formation and growing of precipitates over the RO membrane surface, and about analytical methods to study in a better way the performance of this treatment. In this way, UDTR has recently developed an existing ultrasonic technique for quantitative study of the effect of magnetic fields on $\mathrm{CaCO}_{3}$ scale deposition over NF membranes with encouraging results (Li et al., 2007).

\subsection{Electrochemical methods}

Electrochemical methods allow cleaning membranes at low cross-flow velocity due to the use of potential application between electrodes. Studies done by using this cleaning method are not very extensive and nowadays are not being implemented in any large plant. Some examples of this methodology are found in metallic microfilters cleaning when fouled with albumin and phosphate. Results showed best cleaning performance and recovery when negative current was applied over the microfilter at a low $\mathrm{pH}$ cleaning medium. Even more, changes in $\mathrm{pH}$ near interface due to water reduction and hydrogen gas bubbles also helped membrane cleaning (Webster et al., 2000).

\section{Evaluation of cleaning performance}

Generally, the effectiveness of the cleaning process is checked by measuring the water flux after cleaning at defined operating conditions. However, this is not a reliable measure because a good water flux does not guarantee a good operational flux. In fact, many plant operators have noted that even when the permeate flux is fully restored, it cannot be maintained for as long as when membranes were initially used (Tay \& Song, 2005). Anyway, a low water flux after cleaning may indicate that the cleaning is not sufficient (Tragärdh, 1989).

There are different parameters in the literature for evaluating cleaning efficiency. In some cases, cleaning efficiency is evaluated by the flux recovery and the fouling ratio (Liikanen et al., 2002; Chen et al., 2003): 


$$
\begin{aligned}
& \text { Flux recovery }=J_{c} / J_{0} \\
& \text { Fouling ratio }=J_{f} / J_{0}
\end{aligned}
$$

Where $J_{c}$ is the flux after cleaning, $J_{0}$ is the flux of the virgin membrane, and $J_{f}$ is the flux for the fouled membrane.

The flux recovery has been also defined as (Madaeni et al., 2001):

$$
F R(\%)=\left[\left(J_{c}-J_{w}\right) /\left(J_{0}-J_{w}\right)\right] \cdot 100
$$

Other works evaluate cleaning efficiency in terms of resistance, such as the resistance removal $(R R)$ calculated as (Madaeni et al., 2001):

$$
R R(\%)=\left[\left(R_{f}-R_{c}\right) / R_{f}\right] \cdot 100
$$

Where $R_{f}$ is the resistance after fouling, and $R_{c}$ is the resistance which remains after cleaning. Both resistances can be calculated from the water flux after washing with water, and the water flux after chemical cleaning, respectively.

(Chen et al., 2003) have also considered the enhancement in membrane selectivity by the improvement of TDS rejection calculated as the TDS rejection \% after cleaning minus the TDS rejection \% before cleaning.

\section{Conclusions}

Nowadays, fouling is the most critical phenomenon in membrane performance. Since the economical incidence of fouling can be very significant, minimizing this phenomenon is a must in membrane plants. In spite of methods for preventing fouling, such as good pretreatment and suitable operating conditions, membrane cleaning is always necessary to improve membrane performance over its useful life. Research on membrane cleaning must continue in order to enhance a process that represents an important percentage of the operating costs. Within physical cleaning methods, the use of hypersaline solutions for backwashing and the application of ultrasonic or some kinds of magnetic and electrical fields seem to be very promising techniques in membrane cleaning. With regard to chemical cleaning, research should be focused on the combination with physical methods, such as air flushing, since greater efficiencies can be achieved when combining physical and chemical actions simultaneously.

\section{References}

Ahmad, A.L.; Ibrahim N. \& Bowen W.R. (2002). Automated electrophoretic membrane cleaning for dead-end microfiltration and ultrafiltration. Separation and Purification Technology, Vol. 29, No. 2, (November 2002), pp. 105-112, ISSN 1383-5866

Al-Amoudi, A. \& Lovitt, W.L. (2007). Fouling strategies and the cleaning system of NF membranes and factors affecting cleaning efficiency. Journal of Membrane Science, Vol. 303, Issues 1-2, (October 2007), pp. 4-28, ISSN 0376-7388

Alimi, F.; Tlili, M.M.; Ben Amor, M.; Maurin, G. \& Gabrielli C. (2009) Effect of magnetic water treatment on calcium carbonate precipitation: Influence of the pipe material. Chemical Engineering and Processing, Vol. 48, Issue 8 (August 2009), pp. 1327-1332, ISSN 0255-2701 
Al-Qahtani H. (1996). Effect of magnetic treatment on Gulf seawater. Desalination, Vol. 107, Issue 1, (September 1996), pp. 75-81, ISSN 0011-9164

Ang, W.S.; Lee, S.; Elimelech, M. (2006). Chemical and physical aspects of cleaning of organic-fouled reverse osmosis membranes Journal of Membrane Science, Vol. 272, Issues 1-2, (March 2006), pp. 198-210, ISSN 0376-7388.

Arnal, J.M.; Garcia-Fayos, B.; Sancho, M. \& Verdu, G. (2009a). Ultrafiltration membrane cleaning with different chemical solutions after treating surface water. Desalination and Water Treatment, Vol. 7, Issues 1-3, (July 2009), pp. 198-205, ISSN 1944-3994

Arnal, J.M.; Garcia-Fayos, B.; Sancho, M. \& Verdu, G. (2009b). Cleaning ultrafiltration membranes by different chemical solutions with air bubbles. Desalination and Water Treatment, Vol. 10, Issues 1-3, (October 2009), pp. 198-205, ISSN 1944-3994

Baker, J.S. \& Judd, S.J. (1996). Magnetic amelioration of scale formation. Water Research Vol. 30, Issue 2, (February 1996), pp. 247-260, ISSN 0043-1354

Baker, J.S.; Judd, S.J. \& Parsons A.S. (1997). Antiscale magnetic pretreatment of reverse osmosis feedwater. Desalination Vol. 110, Issues 1-2, (August 1997), pp. 151-166, ISSN 0376-7388

Baker, J.S. \& Dudley, L.Y. (1998). Biofouling in membrane systems_A review. Desalination, Vol. 118, Issues 1-3 (September 1998), pp. 81-90, ISSN 0376-7388

Bartlett, M.; Bird, M.R. \& Howell, J.A. (1995). An experimental study for the development of a qualitative membrane cleaning model. Journal of Membrane Science, Vol. 105, Issues 1-2, (September 1995), pp. 147-157, ISSN 0376-7388

Butt, F.H.; Rahman, F. \& Baduruthamal, U. (1997). Characterization of foulants by autopsy of RO desalination membranes. Desalination, Vol. 114, Issue 1, (December 1997), pp. 51-64, ISSN 0011-9164

Cabassud, C.; Laborie, S.; Durand-Bourlier, L. \& Lainé, J.M. (2001). Air sparging in ultrafiltration hollow fibers: relationship between flux enhancement, cake characteristics and hydrodinamic parameters. Journal of Membrane Science, Vol. 181, Issue 1, (January 2001), pp. 57-69, ISSN 0376-7388

Chen, J.P.; Kim, S.L. \& Ting, Y.P. (2003). Optimization of membrane physical and chemical cleaning by a statistically designed approach. Journal of Membrane Science, Vol. 219, Issues 1-2, (July 2003), pp. 27-45, ISSN 0376-7388

Chen, D.; Weavers, L.K. \& Walker, H.W. (2006). Ultrasonic control of ceramic membrane fouling: effect of particle characteristics. Water Research, Vol. 40, No. 4, (February 2006), pp. 840-850, ISSN 0043-1354

Chesters, S.P. (2009). Innovations in the inhibition and cleaning of reverse osmosis membrane scaling and fouling. Desalination, Vol. 238, Issues 1-3, (March 2009), pp. 22-29, ISSN 0011-9164

Coey, J.M.D. \& Cass S. (2000). Magnetic water treatment. Journal of Magnetism and Magnetic Materials Vol. 209, Issues 1-3, (February 2000), pp 71-74, ISSN 0304-8853

Cornelissen, E.R.; Vrouwenvelder, J.S.; Heijman, S.G.J.; Viallefont, X.D.; Van Der Kooij, D. \& Wessels, L.P. (2007). Periodic air/water cleaning for control of biofouling in spiral wound membrane elements. Journal of Membrane Science, Vol. 287, Issue 1, (January 2007), pp. 94-101, ISSN 0376-7388

Creber, S.A.; Vrouwenvelder,J.S.; van Loosdrecht, M.C.M. \& M.L. Johns. (2010). Chemical cleaning of biofouling in reverse osmosis membranes evaluated using magnetic 
resonance imaging. Journal of Membrane Science, Vol. 362, Issues 1-2, (October 2010), pp. 202-210, ISSN 0376-7388

Cui, Z. \& Taha, T. (2003). Enhancement of ultrafiltration using gas sparging: a comparison of different membrane modules. Journal of Chemical Technology and Biotechnology, Vol. 78, Issues 2-3, (February-March 2003), pp. 249-253, ISSN 1097-4660

Ducom, G. \& Cabassud, C. (2003). Possible effects of air sparging for nanofiltration of salted solutions. Desalination, Vol. 156, Issues 1-3, (August 2003), pp. 267-274, ISSN 00119164

Ebrahim, S. (1994). Cleaning and regeneration of membranes in desalination and wastewater applications: state-of-the-art. Desalination, Vol. 96, Issues 1-3, (June 1994), pp. 225238, ISSN 0011-9164

Feng, D.; van Deventer, J.S.J. \& Aldrich C. (2006). Ultrasonic defouling of reverse osmosis membranes used to treat wastewater effluents. Separation and Purification Technology, Vol. 50, No. 3, (July 2006), pp. 318-323, ISSN 1383-5866

Fritsch, J. \& Morau, C.I. (2008). Development and optimization of a carbon dioxide-aided cold microfiltration process for the physical removal of microorganisms and somatic cells from skim milk. Journal of Dairy Science, Vol. 91, Issue 10 (October 2008), pp. 3744-3760, ISSN: 0022-0302

Gao, W.; Liang, H.; Ma, J.; Chen, Z.; Han, Z. \& Li, G. (2011). Membrane fouling control in ultrafiltration technology for drinking water production: a review. Desalination, Vol. 272, Issues 1-3, (May 2011), pp. 1-8, ISSN 0011-9164

Goosen, M.F.A.; Sablani, S.S.; Al-Hinai, H.; Al-Obeidani, S.; Al-Belushi, R. \& Jackson, D. (2004). Fouling of reverse osmosis and ultrafiltration membranes: a critical review. Separation Science and Technology, Vol. 39, No. 10, pp. 2261-2297, ISSN 0149-6395

Graham, S.I., Reitz, R.L. \& Hickman, C.E. (1989). Improving reverse osmosis performance through periodic cleaning. Desalination, Vol. 74, pp. 113-124, ISSN 0011-9164

Huang, X.; Guillen, G.R. \& Hoek E.M.V. (2010). A new high-pressure optical membrane module for direct observation of seawater RO membrane fouling and cleaning. Journal of Membrane Science, Vol. 364, Issues 1-2, (November 2010), pp. 149-156, ISSN 0376-7388

Iritani, E.; Mukai, Y. \& Kiyotomo Y. (2000). Effects of electric field on dynamic behaviours of dead-end inclined and downward ultrafiltration of protein solutions. Journal of Membrane Science, Vol. 164, Issues 1-2, (January 2000), pp. 51-57, ISSN 0376-7388

Jagannadh, S.N. \& Muralidhara H.S. (2006) Electrokinetics methods to control membrane fouling. Industrial Engineering \& Chemistry Research, Vol. 35, Issue 4, (April 2006), pp. 1133-1140, ISSN 0888-5885

Juang, R.S. \& Lin K.H. (2004). Flux recovery in the ultrafiltration of suspended solutions with ultrasound. Journal of Membrane Science, Vol. 243, Issues 1-2, (November 2004), pp. 115-124, ISSN 0376-7388

Kimura, K.; Hane, Y.; Watanabe, Y.; Amy, G. \& Ohkuma, N. (2004). Irreversible membrane fouling during ultrafiltration of surface water. Water Research, Vol. 38, Issues 14-15, (August-September 2004), pp. 3431-3441, ISSN 0043-1354

Kyllönen, H.M.; Pirkonen, P. \& Nyström M. (2005). Membrane filtration enhanced by ultrasound: a review. Desalination, Vol. 181, Issues 1-3, (September 2005), pp. 319335, ISSN 0011-9164 
Li, J.; Sanderson, R.D. \& Jacobs, E.P. (2002). Non-invasive visualization of the fouling of microfiltration membranes by ultrasonic time-domain reflectometry. Journal of Membrane Science, Vol. 201, Issues 1-2, (May 2002), pp. 17-29, ISSN 0376-7388

Li, J; Liu J.; Yang, T. \& Xiao, C. (2010) Quantitative study of the effect of electromagnetic field on scale deposition on nanofiltration membranes via UTDR. Water Research, Vol. 41, Issue 20, (December 2007), pp. 4595-4610, ISSN 0043-1354

Liberman I. RO membrane cleaning method. PCT, WO 2005/123232 A2 0181497 (2005)

Liberman, B. \& Liberman, I. (2005). Replacing membrane CIP by Direct Osmosis cleaning. Desalination Water Reuse, Vol. 15, No. 1, (August/September 2005), pp. 28-34, ISSN 1022-5404

Liberman, B. Direct osmosis cleaning. Patent application WO 2004/062774 (2004) and U.S. patent application 20070246425 (2007)

Liikanen, R.; Yli-Kuivila, J. \& Laukkanen, R. (2002) Efficiency of various chemical cleanings for nanofiltration membrane fouled by conventionally-treated surface water. Journal of Membrane Science, Vol. 195, Issue 2, (January 2002), pp. 265-276, ISSN 0376-7388.

Lin, J.C-T.; Lee, D-J. \& Huang, C. (2010). Membrane fouling mitigation: Membrane cleaning. Separation Science and Technology, Vol. 45, Issue 7, pp. 858-872, ISSN 0149-6395.

Lu, J.Y.; Du, X. \& Lipscomb G. (2009). Cleaning Membranes with Focused Ultrasound Beams for Drinking Water Treatment, Proceedings of IEEE International Ultrasonics Symposium Proceedings, pp. 1195-1198, ISBN 978-1-4244-4390-1/09, Rome, September, 2009

Madaeni, S.S.; Mohamamdi, T. \& Moghadam, M.K. (2001). Chemical cleaning of reverse osmosis membranes, Desalination, Vol. 134, Issues 1-3, (April 2001), pp. 77-82, ISSN 0011-9164

Mameri, N.; Oussedik, S.; Yeddou, R.; Piron, D.L.; Belhocine, D.; Lounici, H. \& Grib, H. (1999). Enhancement of ultrafiltration flux by coupling static turbulence promoter and electric field. Separation and Purification Technology, Vol. 17, No 3, (December 1999), pp. 203-211, ISSN 1383-5866

Mercier, M.; Fonade, C. \& Lafforgue-Delorme, C. (1997). How slug flow can enhance the ultrafiltration flux in mineral tubular membranes. Journal of Membrane Science, Vol. 128, Issue 1, (May 1997), pp. 103-113, ISSN 0376-7388

Mohammadi, T.; Moghadam, M.K. \& Madaeni, S.S. (2002). Hydrodinamic factors affecting flux and fouling during reverse osmosis of seawater. Desalination, Vol. 151, Issue 3, (January 2003), pp. 239-245, ISSN 0011-9164

Mohammadi, T.; Madaeni, S.S. \& Moghadam, M.K. (2002). Investigation of membrane fouling. Desalination, Vol. 153, Issues 1-3, (February 2003), pp. 155-160, ISSN 00119164

Ngene, I.S.; Lammertink, R.G.H.; Kemperman, A.J.B.; Van de Ven, W.J.C.; Wessels, L.P.; Wessling, M. \& Van der Meer, W.G.J. (2010). $\mathrm{CO}_{2}$ nucleation in membrane spacer channels remove biofilms and fouling deposits. Industrial and Engineering Chemistry Research, Vol. 49, No 20, (September 2010), pp. 10034-10039, ISSN 0888-5885

Oussedik, S.; Belhocine, D.; Grib, H.; Lounici, H.; Piron, D.L. \& Mamer N. (2000). Enhanced ultrafiltration of bovine serum albumin with pulsed electric field and fluidized activated alumina. Desalination, Vol. 127, Issue 1, (January 2000), pp. 59-68, ISSN 0011-9164 
Pontié, M.; Rapenne, S.; Thekkedath, A.; Duchesne, J.; Jacquemet, V.; Leparc, J. \& Suty, H. (2005). Tools for membrane autopsies and antifouling strategies in seawater feeds: a review. Desalination, Vol. 181, Issues 1-3, (September 2005), pp. 75-90, ISSN 00119164

Psoch, C. \& Schiewer, S. (2006). Direct filtration of natural and simulated river water with air sparging and sponge ball for fouling control. Desalination, Vol. 197, Issues 1-3, (October 2006), pp. 190-204, ISSN 0011-9164

Qaisrani, T.M. \& Samhaber, W.M. (2011). Impact of gas bubbling and backflushing on fouling control and membrane cleaning. Desalination, Vol. 266, Issues 1-3, (January 2011), pp. 154-161, ISSN 0011-9164

Qin, J.J.; Liberman, B.; Kekre, K.A. (2009). Direct Osmosis for Reverse Osmosis Fouling Control: Principles, Applications and Recent Developments. The Open Chemical Engineering Journal, Vol. 3, No. 1, pp. 8-16, ISSN 1874-1231

Qin, J.J.; Oo, M. H.; Kekre, K.A. \& Liberman, B. (2010). Development of novel backwash cleaning technique for reverse osmosis in reclamation of secondary effluent. Journal of Membrane Science, Vol. 346, Issue 1, (January 2010), pp. 8-14, ISSN 0376-7388

Ramon, G.; Agnon, Y. \& Dosoretz, C. (2010). Dynamics of an osmotic backwash cycle. Journal of Membrane Science, Vol. 364, Issues 1-2, (November 2010), pp. 157-166, ISSN 0376-7388

Romo, R.F.V., \& Pitts, M.M. Application of electrotehcnology for removal and prevention of reverse osmosis biofouling. Proceedings of AIChE Spring meeting, pp. 1-11, New Orleans (USA), March, 1998

Sadhwani, J.J. \& Veza, J.M. (2001). Cleaning tests for seawater reverse osmosis membranes. Desalination, Vol. 139, Issues 1-3, (September 2001), pp. 177-182, ISSN 0011-9164

Sagiv, A. \& Semiat, R. (2005). Backwash of spiral wound membranes. Desalination, Vol. 179, Issues 1-3, (June 2005), pp. 1-9, ISSN 0011-9164

Sagiv, A. \& Semiat, R. (2010). Parameters affecting backwash variables of RO membranes. Desalination, Vol. 261, Issue 3, (October 2010), pp. 347-353, ISSN 0011-9164

Saxena, A.; Tripathi, B.P.; Kumar M. \& Shahi V. K. (2009) Membrane-based techniques for the separation and purification of proteins: An overview. Advances in Colloid and Interface Science, Vol. 145, Issues 1-2, (January, 2009), pp. 1-22, ISSN 0001-8686

Sennett, P. \& Oliver, J.P. (1965). Colloidal dispersions electrokinetic effects and the concept of zeta potential. Industrial Engineering Chemical, Vol. 57, Issue 8, (August 1965), pp. 32-49, ISSN 0019-7866

Tarazaga, C.C.; Campderros M.E. \& Padilla, A.P. (2006a). Physical cleaning by means of electric field in the ultrafiltration of a biological solution. Journal of Membrane Science, Vol. 278, Issues 1-2, (July 2006), pp. 219-224, ISSN0376-7388

Tarazaga, C.C.; Campderros M.E. \& Padilla, A.P. (2006b). Characterization of exponential permeate flux by technical parameters during fouling and membrane cleaning by electric field. Journal of Membrane Science, Vol. 283, No. 1-2, (October 2006), pp. 339345, ISSN 0376-7388

Tay, K.G. \& Song, L. (2005). A more effective method for fouling characterization in a fullscale reverse osmosis process. Desalination, Vol. 177, Issues 1-3, (June 2005), pp. 95107, ISSN 0011-9164

Tragardh, G. (1989). Membrane cleaning. Desalination, Vol. 71, Issue 3, pp. 325-335, ISSN 0011-9164 
Vedavyasan, C.V. (2001). Potential use of magnetic field a perspective. Desalination Vol. 134, Issues 1-3, (April, 2001), pp. 105-108, ISSN 0011-9164

Vrouwenvelder, J.S.; vanPaassen, J.A.M.; Wessels, L.P.; van Dam, A.F. \& Bakker, S.M. (2006). The Membrane Fouling Simulator: A practical tool for fouling prediction and control. Journal of Membrane Science, Vol. 281, Issues 1-2, (September 2006), pp. 316324, ISSN 0376-7388

Vrouwenvelder, J.S; Bakker, S.M; Wessels, L.P \& vanPaassen, J. A.M. (2007a). The membrane fouling simulator as a new tool for biofouling control of spiral wound membranes. Desalination, Vol. 204, Issues 1-3, (February 2007), pp. 170-174, ISSN 0011-9164

Vrouwenvelder, J.S; Bakker, S.M.; Cauchard, M.; Le Grand, R.; Apacandie, M.; Idrissi, M.; Lagrave, S., Wessels, L.P.; vanPaassen, J.A.M.; Kruithof J.C. \& Van Loosdrecht M.C.M. (2007b). The membrane fouling simulator: a suitable tool for prediction and characterisation of membrane fouling. Water Science and Technology, Vol. 55, Issues 8-9, (September, 2007), pp. 197-205, ISSN 0273-1223

Webster, R.D.; Chilukuri, S.V.V.; Levesley J.A. \& Webster, B.J. (2000). Electrochemical cleaning of microporous metallic filters fouled with bovine serum albumin and phosphate under cross-flow velocities. Journal of Applied Electrochemistry, Vol. 30, Issue 8, (August 2000), pp. 915-924, ISSN 0021-891X

Weigert, T.; Altmann J. \& Ripperger S. (1999). Cross-flow electrofiltration in pilot scale. Journal of Membrane Science, Vol. 159, Issues 1-2, (July 1999), pp. 253-262, ISSN 03767388 


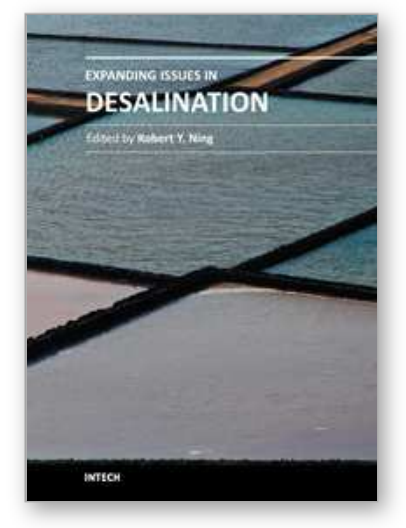

\author{
Expanding Issues in Desalination \\ Edited by Prof. Robert Y. Ning
}

ISBN 978-953-307-624-9

Hard cover, 412 pages

Publisher InTech

Published online 22, September, 2011

Published in print edition September, 2011

For this book, the term â€œdesalinationâ€ is used in the broadest sense of the removal of dissolved, suspended, visible and invisible impurities in seawater, brackish water and wastewater, to make them drinkable, or pure enough for industrial applications like in the processes for the production of steam, power, pharmaceuticals and microelectronics, or simply for discharge back into the environment. This book is a companion volume to â€œDesalination, Trends and Technologiesâ€, INTECH, 2011, expanding on the extension of seawater desalination to brackish and wastewater desalination applications, and associated technical issues. For students and workers in the field of desalination, this book provides a summary of key concepts and keywords with which detailed information may be gathered through internet search engines. Papers and reviews collected in this volume covers the spectrum of topics on the desalination of water, too broad to delve into in depth. The literature citations in these papers serve to fill in gaps in the coverage of this book. Contributions to the knowledge-base of desalination is expected to continue to grow exponentially in the coming years.

\title{
How to reference
}

In order to correctly reference this scholarly work, feel free to copy and paste the following:

José Miguel Arnal, Beatriz Garcia-Fayos and Maria Sancho (2011). Membrane Cleaning, Expanding Issues in Desalination, Prof. Robert Y. Ning (Ed.), ISBN: 978-953-307-624-9, InTech, Available from: http://www.intechopen.com/books/expanding-issues-in-desalination/membrane-cleaning

\section{INTECH}

open science | open minds

\section{InTech Europe}

University Campus STeP Ri

Slavka Krautzeka 83/A

51000 Rijeka, Croatia

Phone: +385 (51) 770447

Fax: +385 (51) 686166

www.intechopen.com

\section{InTech China}

Unit 405, Office Block, Hotel Equatorial Shanghai

No.65, Yan An Road (West), Shanghai, 200040, China

中国上海市延安西路65号上海国际贵都大饭店办公楼405单元

Phone: +86-21-62489820

Fax: $+86-21-62489821$ 
(C) 2011 The Author(s). Licensee IntechOpen. This chapter is distributed under the terms of the Creative Commons Attribution-NonCommercialShareAlike-3.0 License, which permits use, distribution and reproduction for non-commercial purposes, provided the original is properly cited and derivative works building on this content are distributed under the same license. 